\title{
Toughness Differentiation of Welded Low Carbon Steel by Using Baked Low Hydrogen Electrode (E7018) and Low Hydrogen Electrode Without Baking Process
}

\section{Perbedaan Ketangguhan Hasil Las Baja Karbon Rendah dengan Menggunakan Elektroda Low Hydrogen (E7018) Yang Dipanaskan dengan Yang Tidak Dipanaskan}

\author{
Prasetya Didi Rahman ${ }^{1 *}$, Jasman ${ }^{1}$, Nofri Helmi ${ }^{1}$
}

\begin{abstract}
Low hydrogen electrode known as lime type, due lime ferritic or lime flourspar countain. This research purpose to know influence of toughness welding result by using baked low hydrogen electrode on low carbon steel. This is an experimental research. After the test obtained the average potential energy

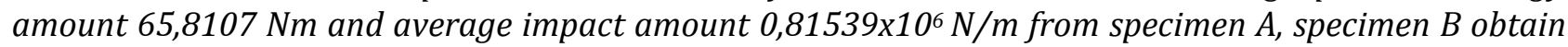
average potential energy amount $81,9396 \mathrm{Nm}$ and average impact amount $1,00251 \times 10^{6} \mathrm{~N} / \mathrm{m}$, and spesimen D obtain average potential energy amount $92,5795 \mathrm{Nm}$ and average impact amount $1,13445 \times 10^{6} \mathrm{~N} / \mathrm{m}$. The most tough specimen in C group, with average potential energy amount 126,3913 $\mathrm{Nm}$ and average impact amount $1,56703 \times 10^{6} \mathrm{~N} / \mathrm{m}$.
\end{abstract}

Keywords

Baking Electrode, Low Hydrogen Electrode, Welding, Impact Test, Low Carbon Steel

\begin{abstract}
Abstrak
Elektroda low hydrogen disebut juga dengan jenis kapur, katena bahan utama yang digunakan adalah kapur dan fluorat. Tujuan penilitian ini adalah mengetahui apakah ada pengaruh variasi temperatur pemanasan elektroda low hydrogen sebelum pengelasan terhadap ketangguhan hasil las pada baja karbon rendah. Metode yang digunakan adalah metode eksperimen. Didapatkan hasil eksperimen nilai rerata serapan energi sebesar 65,8107 $\mathrm{Nm}$ dan rerata harga impak sebesar $0,81539 \times 10^{6} \mathrm{~N} / \mathrm{m}$ pada spesimen A, spesimen B didapat nilai rerata serapan energi sebesar 81,9396 Nm dan rata-rata harga impak sebesar 1,00251×106 N/m dan spesimen D nilai rerata serapan energi sebesar 92,5795 $\mathrm{Nm}$ dan rerata harga impak sebesar $1,13445 \times 10^{6} \mathrm{~N} / \mathrm{m}$. Hasil terbaik terdapat pada kelompok C denga rerata nilai serapan energi 126,3913 Nm dengan harga impak 1,56703×106 N/m.
\end{abstract}

\section{Kata Kunci}

Pemanasan Elektroda, Elektroda Hidrogen Rendah, Pengelasan, Uji Ketangguhan, Baja Karbon Rendah

1 Jurusan Teknik Mesin, Fakultas Teknik, Universitas Negeri Padang

Kampus UNP Air Tawar, Padang 25131, Indonesia

*pras.bigcartel@gmail.com

Submitted : December 12, 2018. Accepted : January 02, 2019. Published : January 15, 2019 


\section{PENDAHULUAN}

Definisi pengelasan menurut DIN (Deutsche Industrie Normen) adalah ikatan metalurgi pada sambungan logam atau logam paduan yang dilaksanakan dalam keadaan lumer atau cair. Dengan kata lain, las adalah suatu cara untuk menyambung benda padat dengan cara mencairkannya melalui pengelasan. Untuk berhasilnya penyambungan logam oleh las diperlukan beberapa syarat yang harus dipenuhi, yaitu benda yang akan dilas dapat mencair/melebur oleh panas, antara benda-benda yang disambung terdapat kesesuaian sifat lasnya sehingga tidak melemahkan atau menggagalkan sambungan tersebut dan cara-cara penyambungan sesuai dengan sifat benda padat dan tujuan penyambungannya [1].

\section{DASAR TEORI}

Pengelasan terbagi menjadi banyak jenis, namun yang lazim digunakan adalah pengelasan las listrik elektroda terbungkus (Shielded Metal Arc Welding). Pengelasan ini menggunakan busur nyala listrik sebagai sumber panas untuk mencairkan elektroda atau bahan tambah. Elektroda yang digunakan dalam pengelasan ini berbentuk kawat yang dilindungi dengan lapisan zat pelindung (flux) yang ikut mencair dan mengisolasi bahan tambah tersebut dari udara luar sewaktu pengelasan. Fungsi lain dari salutan pada elektroda untuk menstabilkan busur listrik, oleh karena itu diperlukan penanganan khusus pada elektroda khususnya pada elektroda low hydrogen (E7015, E7016, E7018, E7028 dan E7048) kandungan air maksimum yang berada di lapisan pelindung elektroda baja karbon ini tidak boleh melebihi $0,6 \%$ dari berat sebagai mana aslinya dari pabrik pembuat atau setelah kondisi fisiknya diperbaiki kembali. Apabila elektroda low hydrogen diterima dalam kondisi kurang meyakinkan atau tidak cukup terlindung dari kelembaban sewaktu penyimpanan, maka elektroda harus dipanaskan sebelum dipakai kembali, pada suhu 500으 $\mathrm{F}$ hingga $800^{\circ} \mathrm{F}$ atau $260^{\circ} \mathrm{C}$ hingga $425^{\circ} \mathrm{C}$ selama 1-2 jam (American Welding Society, 2004).

Pemilihan elektroda dalam pengelasan belum tentu diketahui oleh semua juru las, bahkan tidak sedikit juru las yang mengetahui prosedur pemanasan dan penyimpanan elektroda tetapi mengabaikan prosedur pemanasan dan penyimpanan elektroda low hydrogen tersebut, dan juga tidak semua bengkel konstruksi memiliki pemanas elektroda terutama bengkelbengkel kecil karena mahalnya alat tersebut.

Berdasarkan uraian di atas, maka penulis ingin mengungkapkan tentang perbedaan ketangguhan hasil las baja karbon rendah dengan menggunakan Elektroda Low Hydrogen (E7018) yang dipanaskan dengan yang tidak dipanaskan.

\section{METODE PENELITIAN}

Penelitian ini membandingkan ketangguhan logam yang dilas menggunakan elektroda low hydrogen E7018 yang dipanaskan di dalam baking oven dengan suhu $260^{\circ} \mathrm{C}, 343^{\circ} \mathrm{C}$, $425^{\circ} \mathrm{C}$ dengan elektroda yang tidak dipanaskan pada baja ASTM A36. Objek yang diteliti diuji ketangguhannya menggunakan alat uji ketangguhan (impact tester) dengan metode charpy.

\section{HASIL DAN PEMBAHASAN}

Pengujian dilakukan terhadap 12 spesimen yang diantaranya 9 spesimen dilas menggunakan elektroda yang dipanaskan dengan variasi suhu $260^{\circ} \mathrm{C}, 343^{\circ} \mathrm{C}, 425^{\circ} \mathrm{C}$ dan 3 spesimen dilas menggunakan elektroda tanpa pemanasan. 


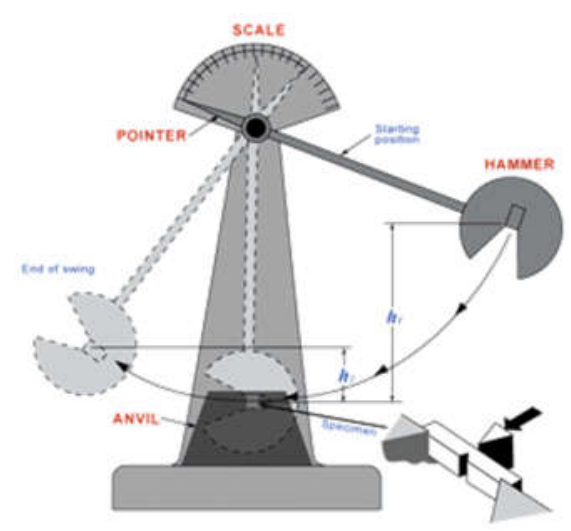

Gambar 1. Skema Uji Impak
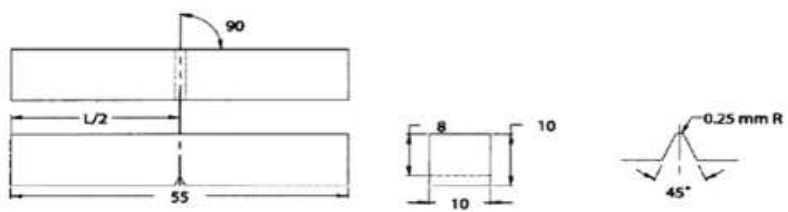

Gambar 2. Spesimen Uji Impact Charpy V Notch [2].

Proses pengerjaan dimulai dari pemanasan dan penanganan elektroda, pengukuran dan pemotongan bahan las, pengelasan, pembuatan spesimen uji, pengujian, dan analisa data.

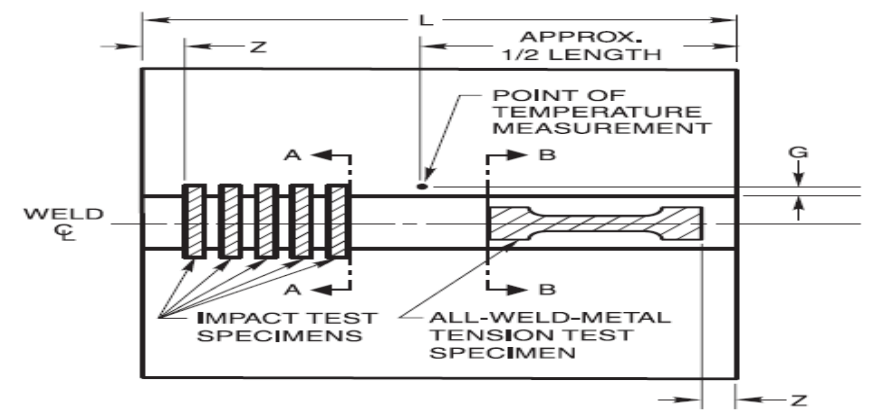

Gambar 3. Lokasi Spesimen Pengujian pada Material Las[3] (AWS, 2004:9)

Pengujian dimulai dengan menaikkan lengan pendulum hingga terbentuk sudut $140^{0}$ sebagai sudut $\alpha$, spesimen diletakkan pada landasan dengan takikan mengarah ke belakang pendulum. Pastikan jarum penunjuk sudut $\alpha$ dan $\beta$ diposisi yang sama kemudian lepaskan pendulum hingga berbenturan dengan spesimen, selanjutnya baca angka yang ditunjukkan pada jarum. Angka yang ditunjukkan merupakan sudut pantulan yang digunakan untuk mencari tinggi pantulan dengan menggunakan persamaan:

$$
\begin{aligned}
& h_{1}=r+r \sin \theta\left(\text { jika } \beta>90^{\circ}\right) \\
& h_{1}=\frac{\beta}{90^{\circ}} S\left(\text { jika } \beta<\text { dari } 90^{\circ}\right) \\
& \sin \theta=\beta-90^{\circ}
\end{aligned}
$$


Tinggi jatuh dapat ditentukan terlebih dahulu karena sudut jatuh merupakan sebuat ketatapan, dapat dicari dengan persamaan:

$$
\begin{aligned}
& h_{0}=r+r \sin \theta \\
& \sin \theta=\propto-90^{\circ}
\end{aligned}
$$

Energi serapan yang dibutuhkan untuk mematahkan benda uji, dapat diketahui dengan persamaan:

$$
\begin{aligned}
& E=E_{0}-E_{I} \\
& E_{0}=m \times g \times h_{0} \\
& E_{I}=m \times g \times h_{I}
\end{aligned}
$$

Energi serapan yang mematahkan benda uji persatuan luas penampang patahan disebut dengan harga impak, dapat diketahui dengan persamaan :

$$
H_{I}=\frac{E}{A}
$$

Dimana:

$$
\begin{aligned}
& \mathrm{E}=\text { Energi Serapan }(\mathrm{Nm}) \\
& \mathrm{E}_{0}=\text { Energi Jatuh }(\mathrm{Nm}) \\
& \mathrm{E}_{1}=\text { Energi Pantulan (Nm) } \\
& H_{1}=\operatorname{Harga} \operatorname{Impak}(N / m) \\
& m \text { = Massa Bandul }(22 \mathrm{Kg}) \\
& \mathrm{g}=\operatorname{Gravitasi}(9,81 \mathrm{~m} / \mathrm{s}) \\
& \mathrm{h}_{0}=\text { Tinggi Jatuh }(\mathrm{m}) \\
& \mathrm{h}_{1}=\text { Tinggi Pantulan (m) } \\
& \alpha=\text { Sudut Jatuh (140) } \\
& \beta=\text { Sudut Pantul (ㅇ) } \\
& A=\text { Luas Penampang }\left(\mathrm{m}^{2}\right)
\end{aligned}
$$

Percobaan dilakukan sebanyak 3 kali untuk setiap kelompok spesimen, maka untuk menghitung rata-rata serapan energi dan rata-rata harga impak dapat dihitung dengan:

$$
M=\frac{\sum x}{n}
$$

\section{Dimana:}

$$
\begin{aligned}
& M=\text { Mean (rata-rata) } \\
& \sum x=\text { Jumlah data } \\
& n \quad \text { = Jumlah spesimen }
\end{aligned}
$$




\section{Hasil}

Eksperimen telah dilakukan dan hasilnya dicatat kemudian dipindahkan ke dalam tabel hasil pengujian seperti pada Tabel 1.

Tabel 1. Hasil Pengujian Impact

\begin{tabular}{|c|c|c|c|c|c|c|c|c|c|c|}
\hline \multirow{2}{*}{ No. } & \multirow{2}{*}{ Spesimen } & \multirow{2}{*}{$\begin{array}{l}\text { Luas } \\
\text { penampang } \\
\left(\mathrm{m}^{2}\right)\end{array}$} & \multicolumn{2}{|c|}{$\begin{array}{c}\text { Sudut } \\
\left({ }^{\circ}\right)\end{array}$} & \multicolumn{2}{|c|}{$\begin{array}{l}\text { Tinggi bandul } \\
(\mathrm{m})\end{array}$} & \multirow{2}{*}{$\begin{array}{l}\text { Serapan } \\
\text { energi } \\
(\mathrm{Nm})\end{array}$} & \multirow{2}{*}{$\begin{array}{c}\text { Harga } \\
\text { impak } \\
\left(\times 10^{6} \mathrm{~N} / \mathrm{m}\right)\end{array}$} & \multirow{2}{*}{$\begin{array}{c}\text { Rata-rata } \\
\text { serapan energi } \\
(\mathrm{Nm})\end{array}$} & \multirow{2}{*}{$\begin{array}{c}\text { Rata-rata } \\
\text { harga impak } \\
\left(\times 10^{6} \mathrm{~N} / \mathrm{m}\right)\end{array}$} \\
\hline & & & $\alpha$ & $\beta$ & $\mathrm{h}_{0}$ & $\mathrm{~h}_{\mathrm{i}}$ & & & & \\
\hline 1 & \multirow{3}{*}{$\begin{array}{c}\text { A (Elektroda tanpa } \\
\text { perlakuan) }\end{array}$} & $80 \times 10^{-6}$ & 140 & 116 & 1,4128 & 1.1504 & 56,6311 & 0,70789 & \multirow{3}{*}{65,8107} & \multirow{3}{*}{0,81539} \\
\hline 2 & & $81 \times 10^{-6}$ & 140 & 110 & 1,4128 & 1,0736 & 73,2061 & 0,90378 & & \\
\hline 3 & & $81 \times 10^{-6}$ & 140 & 112 & 1,4128 & 1,0996 & 67,5948 & 0,83450 & & \\
\hline 1 & \multirow{3}{*}{$\begin{array}{c}\text { B (Elektroda } \\
\text { dipanaskan pada } \\
\left.\text { suhu } 260^{\circ} \mathrm{C}\right)\end{array}$} & $82 \times 10^{-6}$ & 140 & 103 & 1,4128 & 0,9799 & 93,4284 & 1,13937 & \multirow{3}{*}{81,9396} & \multirow{3}{*}{1,00251} \\
\hline 2 & & $81 \times 10^{-6}$ & 140 & 113 & 1,4128 & 1,1125 & 64,8107 & 8,0013 & & \\
\hline 3 & & $82 \times 10^{-6}$ & 140 & 105 & 1,4128 & 1,0070 & 87,5797 & 1,06804 & & \\
\hline 1 & \multirow{3}{*}{$\begin{array}{c}\mathrm{C}(\text { Elektroda } \\
\text { dipanaskan pada } \\
\left.\text { suhu } 343^{\circ} \mathrm{C}\right)\end{array}$} & $81 \times 10^{-6}$ & 140 & 82 & 1,4128 & 0,7288 & 147,6208 & 1,82247 & \multirow{3}{*}{126,3913} & \multirow{3}{*}{1,56703} \\
\hline 2 & & $81 \times 10^{-6}$ & 140 & 100 & 1,4128 & 0,9388 & 102,2986 & 1,26294 & & \\
\hline 3 & & $80 \times 10^{-6}$ & 140 & 91 & 1,4128 & 0,8139 & 129,2546 & 1,61568 & & \\
\hline 1 & \multirow{3}{*}{$\begin{array}{c}\text { D (Elektroda } \\
\text { dipanaskan pada } \\
\left.\text { suhu } 425^{\circ} \mathrm{C}\right)\end{array}$} & $82 \times 10^{-6}$ & 140 & 109 & 1,4128 & 1,0604 & 76,0548 & 0,92750 & \multirow{3}{*}{92,5795} & \multirow{3}{*}{1,13445} \\
\hline 2 & & $82 \times 10^{-6}$ & 140 & 103 & 1,4128 & 0,9799 & 93,4284 & 1,13937 & & \\
\hline 3 & & $81 \times 10^{-6}$ & 140 & 98 & 1,4128 & 0,9112 & 108,2553 & 1,33648 & & \\
\hline
\end{tabular}

\section{Pembahasan}

Data yang ditunjukkan pada tabel menunjukkan elektroda yang digunakan pada spesimen A tidak dipanaskan terlebih dahulu, didapat nilai serapan energi dan harga impak spesimen 1 sebesar 56,6331 $\mathrm{Nm}$ dengan harga impak 0,70789x106 N/m, spesimen 2 sebesar 73,2061 Nm dan $0,90378 \times 10^{6} \mathrm{~N} / \mathrm{m}$, dan spesimen 3 sebesar 67,5948 $\mathrm{Nm}$ dan 0,83450x106 N/m. Sehingga didapat nilai rata-rata serapan energi sebesar 65,8107 $\mathrm{Nm}$ dan rata-rata harga impak sebesar $0,81539 \times 10^{6} \mathrm{~N} / \mathrm{m}$.

Elektroda yang digunakan pada spesimen B dipanaskan pada suhu $260^{\circ} \mathrm{C}$ terlebih dahulu, dari hasil pengujian didapat nilai serapan energi dan harga impak spesimen 1 sebesar 93,4284 $\mathrm{Nm}$ dengan harga impak 1,13937x $10^{6} \mathrm{~N} / \mathrm{m}$, spesimen 2 sebesar 64,8107 $\mathrm{Nm}$ dan $0,80013 \times 10^{6} \mathrm{~N} / \mathrm{m}$, dan spesimen 3 sebesar 87,5797 Nm dan 1,06804x106 N/m. Sehingga didapat nilai rata-rata serapan energi sebesar 81,9396 $\mathrm{Nm}$ dan rata-rata harga impak sebesar $1,00251 \times 10^{6} \mathrm{~N} / \mathrm{m}$.

Elektroda yang digunakan pada spesimen C dipanaskan pada suhu $343^{\circ} \mathrm{C}$ terlebih dahulu, dari hasil pengujian didapat nilai serapan energi dan harga impak spesimen 1 sebesar 147,6208 Nm dengan harga impak 1,82247x106 N/m, spesimen 2 sebesar 102,2986 Nm dan $1,26294 \times 10^{6} \mathrm{~N} / \mathrm{m}$, dan spesimen 3 sebesar 129,2546 Nm dan 1,61568x106 N/m. Sehingga didapat nilai rata-rata serapan energi sebesar 126,3913 Nm dan rata-rata harga impak sebesar $1,56703 \times 10^{6} \mathrm{~N} / \mathrm{m}$.

Elektroda yang digunakan pada spesimen D dipanaskan pada suhu 4250 $\mathrm{C}$ terlebih dahulu, dari hasil pengujian didapat nilai serapan energi dan harga impak spesimen 1 sebesar

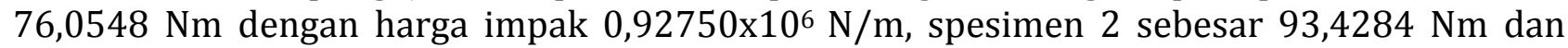
$1,13937 \times 10^{6} \mathrm{~N} / \mathrm{m}$, dan spesimen 3 sebesar 108,2553 Nm dan 1,33648 $\mathrm{N} / \mathrm{m}$. Sehingga 
didapat nilai rata-rata serapan energi sebesar 92,5795 $\mathrm{Nm}$ dan rata-rata harga impak sebesar $1,13445 \times 10^{6} \mathrm{~N} / \mathrm{m}$.

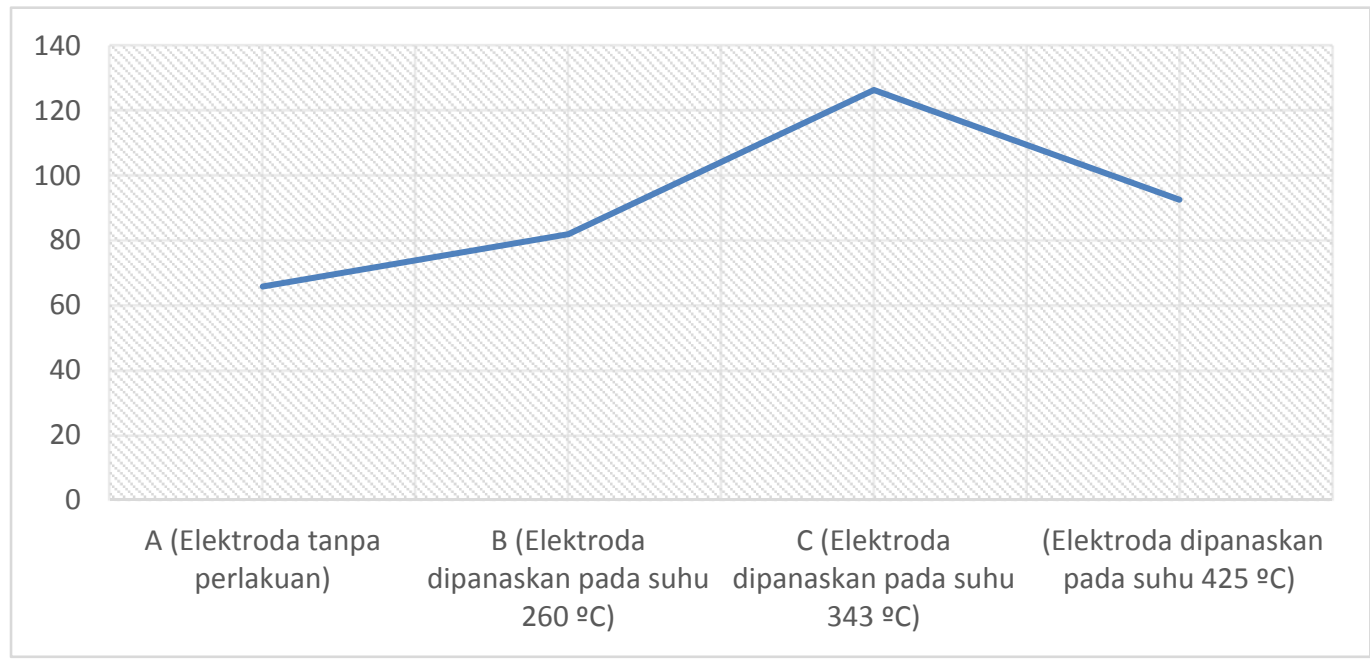

Gambar 4. Grafik Rata-rata Serapan Energi Setiap Kelompok

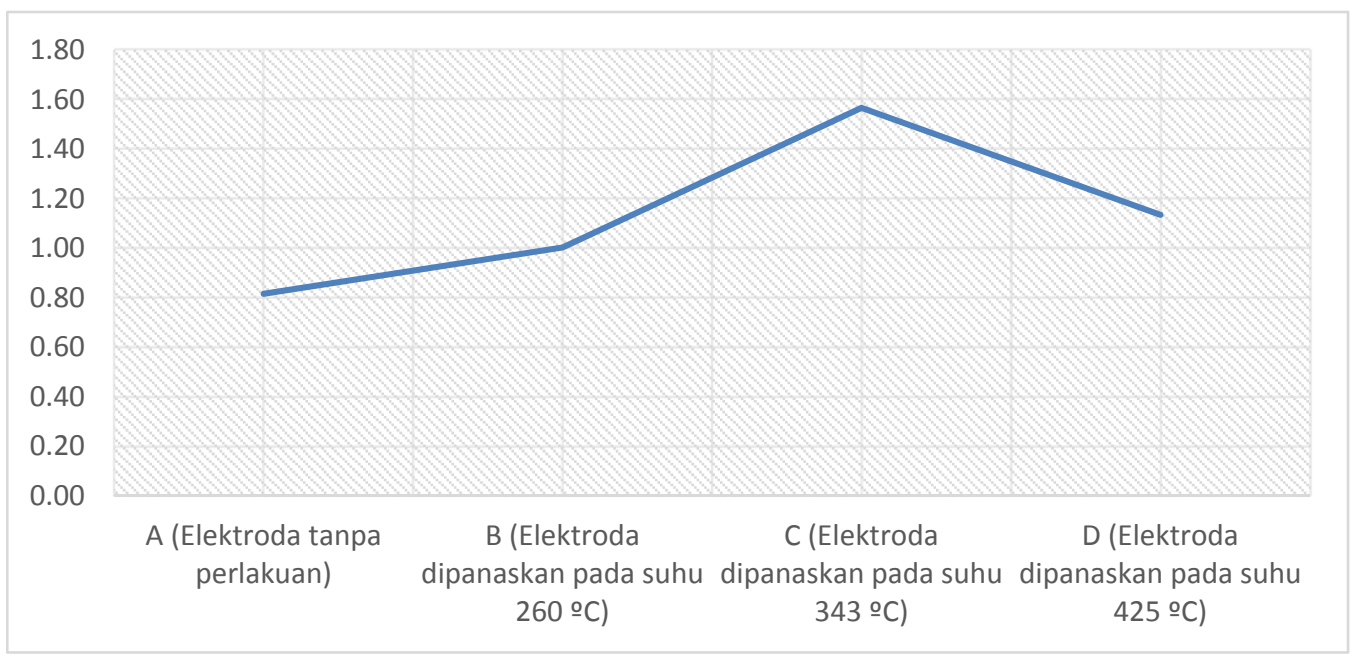

Gambar 5. Grafik Rata-rata Harga Impak setiap Kelompok

Grafik diatas menunjukkan bahwa nilai serapan energi dan harga impak pada setiap spesimen yang dilas menggunakan dengan elektroda dipanaskan mengalami peningkatan nilai serapan energi dan harga impak, yang dimana rata-rata serapan energi dan rata-rata harga impak tertinggi berada pada kelompok spesimen $\mathrm{C}$ sebagai batas tengah dari interval suhu pemanasan elektroda low hydrogen sebesar 260-425으, sedangkan pada batas bawah yaitu $260{ }^{\circ} \mathrm{C}$ dan batas atas $425^{\circ} \mathrm{C}$ nilai rata-rata serapan energi dan rata-rata harga impak tidak setinggi batas tengah, adapun faktor-faktor yang mempengaruhi hal tersebut yaitu: mesin yang tidak terkalibrasi dan adanya cacat las pada spesimen.

\section{SIMPULAN}

\section{Simpulan}

Berdasarkan hasil dari pengujian impak, dapat diambil kesimpulan bahwa hasil pengelasan dipengaruhi oleh persiapan pada sebelum pengelasan, salah satunya adalah pemanasan elektroda low hydrogen sebelum pengelasan. Pemanasan pada elektroda low 
hydrogen bertujuan untuk mengurangi atau memastikan bahwa kadar hidrogen dalam selaput elektroda berada pada standar yang ditentukan, sehingga memberikan pengaruh terhadap ketangguhan dan sifat mekanik lainnya pada hasil pengelasan baja karbon rendah.

Hasil pengujian ketangguhan spesimen A memiliki rata-rata energi serapan 65,8107 Nm dengan rata-rata harga impak 0,81539x106 N/m, spesimen B didapat rata-rata nilai serapan energi 81,9396 Nm dengan rata-rata harga impak 1,00251x106 N/m, spesimen C didapat rata-rata nilai serapan energi 126,3913 Nm dengan harga impak 1,56703x106 N/m, untuk spesimen D didapat rata-rata nilai serapan energi 92,5795 Nm dan harga impak 1,13445x106 $\mathrm{N} / \mathrm{m}$.

Spesimen yang dilas menggunakan elektroda yang dipanaskan sebelum pengelasan memiliki nilai rata-rata serapan energi dan harga impak yang lebih tinggi daripada spesimen yang dilas dengan elektroda tanpa perlakuan.

\section{DAFTAR RUJUKAN}

[1] Sriwidharto. (1987). Petunjuk Kerja Las. Jakarta: Pradya Paramita.

[2] ASTM International. (2011). Standard Test Methods for Notched Bar Impact Testing of Metallic Materials ${ }^{1}$. Pennsylvania: ASTM International.

[3] AWS. (2004). AWS A5.1: Specification for Carbon Steel Electrodes for Shielded Metal Arc Welding. Florida: AWS 
